ANNALS OF “DUNAREA DE JOS” UNIVERSITY OF GALATI
MATHEMATICS, PHYSICS, THEORETICAL MECHANICS
FASCICLE II, YEAR XII (XLIII) 2020, No. 1
DOI: https://doi.org/10.35219/ann-ugal-math-phys-mec.2020.1.05

\title{
Water quality analysis within a rural locality distribution network
}

\author{
Cristina-Mihaela Vîrlan (Toma) ${ }^{1, *}$, Daniel Toma ${ }^{1}$, Florian Stătescu ${ }^{1}$, \\ Costel-Cătălin Prăjanu ${ }^{1}$
}

\author{
1 "Gheorghe Asachi” Technical University of Iasi, Faculty of Hydrotechnical Engineering, Geodesy and \\ Environmental Engineering, Department of Hydroamelioration and Environmental Protection, 65 Prof. dr. \\ docent Dimitrie Mangeron Street, 700050, Iasi, Romania \\ *Corresponding author: cristinavirlan23@yahoo.com
}

\begin{abstract}
The law on drinking water quality aims to protect human health against the effects of any type of contamination by ensuring its quality of clean and health-safe water. Many cases of illness in populations are due to the fact that in their community there is no strict regulation and control regarding the water quality at the source which supplies their water systems. Thus, special importance must be given to the drinking water supply in rural areas, considering that a large part of populated centers within this category do not benefit from centralized drinking water systems. This paper will analyze a small distribution network within a commune in Suceava County. Hydraulic and water quality analysis calculations in the distribution network were performed by means of the EPANET 2.0 software. For the water quality analysis, a surveyed factor was the variation in time of free residual chlorine concentration, this parameter being monitored along with the distribution network (corresponding both to a first order reaction in the fluid volume and at pipe wall, and to a second order reaction within the fluid volume). The hourly water consumption on a working day was considered in compliance with the Romanian standards for villages and rural areas, and the simulation was performed for a period of 72 hours.
\end{abstract}

Keywords: chlorine concentration decay, drinking water network, EPANET, water quality modeling.

\section{INTRODUCTION}

Drinking water supply requires raw water abstraction and treatment, followed by storage, transport, and distribution of finished water. The water treatment processes are selected and adapted to purify water for drinking purposes based on the quality of the incoming water and the quality standards of the drinking water to comply with. Further, the produced drinking water is distributed through extended drinking water transport and distribution systems. Worldwide, the biological stability of drinking water is maintained either by limiting nutrient concentrations or by applying a disinfectant residual to minimize the regrowth of microorganisms [1].

Drinking water utilities invest considerable resources in producing safe drinking water. Most of this effort and much of the accompanying water quality monitoring occur at drinking water treatment plants. However, after exiting a water treatment plant and before delivery to a customer's tap, there are numerous opportunities for water quality changes. These include potential reactions with disinfection residuals and concurrent formation of disinfection by-products (DBPs), presenting additional public health risks [2].

The protection of water quality means preservation, respectively the improvement of the physicochemical and biological characteristics of waters in order to provide their most efficient management [3]. Both Directive 98/83/EC and the law on drinking water quality divide the parameters that must be analyzed and observed into microbiological parameters, chemical parameters, and indicator parameters [4]. The main causes that determine the degradation of water quality in 
distribution systems can be: the formation and development of a biological ecosystem, the quality of network/pipes materials, the water stagnation in network, the building of deposits, or accidental contamination.

Chlorine is used both as a primary disinfectant in water treatment plants, both for the destruction of bacteria and viruses, as well as to prevent the development of micro-organisms in water distribution systems [5].

Modelling a water distribution system allows predicting the effects of operational and physical changes on both Hydraulic and Water Quality parameters. Hydraulic parameters such as flow rates and heads are commonly monitored via telemetry. However, water quality parameters are commonly sampled monthly or annually and only at specific nodes in the water distribution system. A computer model of a water distribution system can thus reveal a great deal of information regarding water quality characteristics. EPANET is a widely used simulation software for Hydraulic analysis and Water Quality analysis in water distribution systems [6].

\section{MATERIALS AND METHODS 2.1. THE EPANET PROGRAM}

The hydraulic and quality simulation of water in distribution networks was performed with the EPANET 2.0 program. This program was developed by the US-EPA Environmental Protection Agency and contains an integrated environment for input data editing and viewing of results in various forms (graphs, maps, tables). The software allows the tracking of flow variations in each pipe, pressures in nodes, but also the chemical loads' concentrations during the simulation.

EPANET 2.0 offers the following capabilities of water quality modeling: models the movement of a non-reactive material through the network in the unit of time; models the movement and evolution of a reactive material highlighting its increase or decrease over time; models water quality in a network in terms of its age; monitors what percentage of the flow from one node reaches the other nodes in time (a certain time increment is required for the analysis); models both the actual flow in the pipe's core and the flow in the vicinity of pipe walls; allows the reactions to decrease or increase to an imposed concentration limit; uses adjustable global reaction coefficients; allows the variation of concentration in time in any network point; provides the modeling of water accumulation in tanks [7].

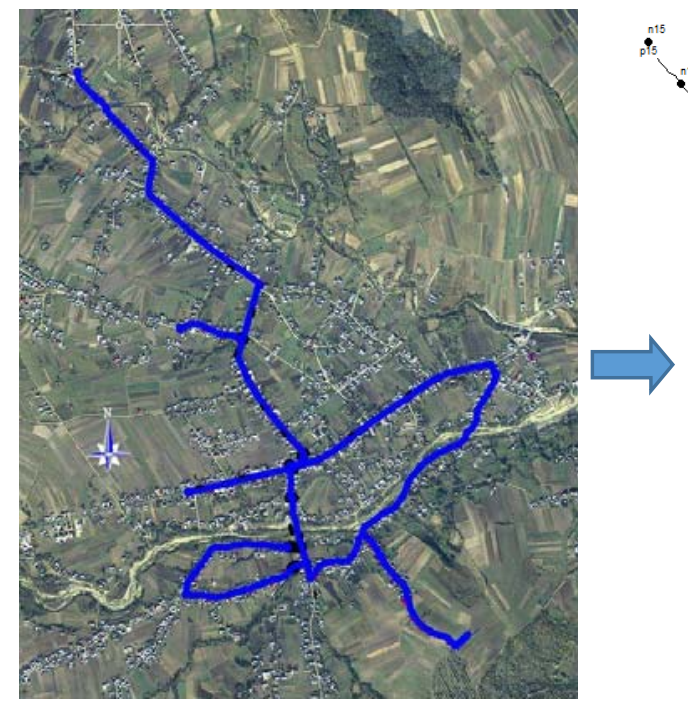

a) .dwg format

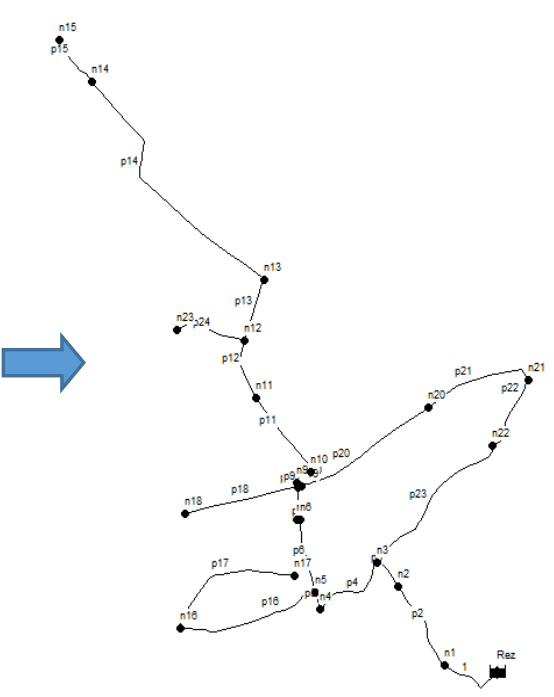

b) .inp format

\section{Fig. 1. The water supply diagram - Conversion from .dwg format into .inp format with EpaCAD}

In order to arrive at the EPANET simplified scheme, the network pipes based on the Stereo '70 coordinate orthophotoplan were first drawn in AutoCAD. AutoCAD is one of the most used programs for managing technical drawings conceived for the design, construction, and operation of 
water supply systems. By means of the EpaCAD program, the AutoCAD file (the .dwg extension) is converted into an EPANET file (the .inp extension). This program was developed by ITA, the Polytechnic University of Valencia and is able to automatically import the main properties of elements, providing mostly the information needed to build a network.

\subsection{CASE STUDY DESCRIPTION}

The water supply system diagram includes a $300 \mathrm{~m}^{3}$ storage tank and a PN10 HDPE pipe distribution network, which is a mixed network consisting of an annular network, with branches in certain nodes. The studied distribution network corresponds to a settlement of 4000 inhabitants from Suceava county and was sized for an daily maximum flow of $7.66 \mathrm{~L} / \mathrm{s}$. In the system, there is a need to ensure a minimum pressure of 1.2 bar because the locality does not feature housings larger than a $\mathrm{GF}+1$ configuration. According to Figure 1.b) the network includes 24 sections (pipes) with diameters between 110 and $160 \mathrm{~mm}$, in a total length of $8.240 \mathrm{~m}$ and 23 intersection nodes.

The geometric characteristics of the network (lengths, diameters, roughness) are directly entered in the program, where the same absolute roughness of $0.007 \mathrm{~mm}$ was considered for all polyethylene pipes (the system is newly commissioned).

Table 1. Geometrical pipe features

\begin{tabular}{|c|c|c|c|}
\hline No. & $\begin{array}{c}\text { ID } \\
\text { EPANET }\end{array}$ & $\begin{array}{c}\text { Length } \\
(\mathbf{m})\end{array}$ & $\begin{array}{c}\text { Diameter } \\
\text { (mm) }\end{array}$ \\
\hline $\mathbf{1}$ & p1 & 269.6 & 160 \\
$\mathbf{2}$ & p2 & 384.8 & 160 \\
$\mathbf{3}$ & p3 & 136.2 & 160 \\
$\mathbf{4}$ & p4 & 349.7 & 160 \\
$\mathbf{5}$ & p5 & 70.7 & 140 \\
$\mathbf{6}$ & p6 & 307.4 & 140 \\
$\mathbf{7}$ & p7 & 16.05 & 140 \\
$\mathbf{8}$ & p8 & 136.5 & 140 \\
$\mathbf{9}$ & p9 & 16.8 & 125 \\
$\mathbf{1 0}$ & p10 & 113.4 & 125 \\
$\mathbf{1 1}$ & p11 & 389.0 & 125 \\
$\mathbf{1 2}$ & p12 & 255.0 & 125 \\
$\mathbf{1 3}$ & p13 & 257.6 & 125 \\
$\mathbf{1 4}$ & p14 & 1148.0 & 125 \\
$\mathbf{1 5}$ & p15 & 227.7 & 110 \\
$\mathbf{1 6}$ & p16 & 601.9 & 125 \\
$\mathbf{1 7}$ & p17 & 604.6 & 110 \\
$\mathbf{1 8}$ & p18 & 487.5 & 125 \\
$\mathbf{1 9}$ & p19 & 13.23 & 140 \\
$\mathbf{2 0}$ & p20 & 634.1 & 140 \\
$\mathbf{2 1}$ & p21 & 479.6 & 125 \\
$\mathbf{2 2}$ & p22 & 320.6 & 140 \\
$\mathbf{2 3}$ & p23 & 714.0 & 140 \\
$\mathbf{2 4}$ & p24 & 304.5 & 110 \\
\hline
\end{tabular}

The daily flow varies depending on the time interval. In this sense, the study used the hourly variation coefficients depending on the locality's size [8]. Table 2 presents these coefficients for localities with populations of less than 10.000 inhabitants, and in EPANET these coefficients are entered as a graph of hourly flow variation.

Table 2. Hourly variation coefficients, during a working day, for villages, at time $t(h)$

\begin{tabular}{|c|cccccccccccc|}
\hline $\mathrm{t}$ & $0: 00$ & $1: 00$ & $2: 00$ & $3: 00$ & $4: 00$ & $5: 00$ & $6: 00$ & $7: 00$ & $8: 00$ & $9: 00$ & $10: 00$ & $11: 00$ \\
\hline $\mathrm{q}(\mathrm{t})$ & 0.24 & 0.12 & 0.12 & 0.12 & 0.12 & 1.56 & 2.88 & 2.04 & 0.84 & 0.72 & 0.72 & 1.08 \\
\hline $\mathrm{t}$ & $12: 00$ & $13: 00$ & $14: 00$ & $15: 00$ & $16: 00$ & $17: 00$ & $18: 00$ & $19: 00$ & $20: 00$ & $21: 00$ & $22: 00$ & $23: 00$ \\
\hline
\end{tabular}




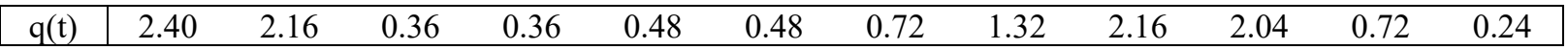

\subsection{WATER QUALITY ANALYSIS}

The equations that govern the water quality analysis are based on the principles of mass conservation, combined with kinetic reactions. When a compound transits a water-filled pipe, reactions occur between the pipe and the organic compounds from the fluid. In the flowing stream inside a pipe, the dissolved substances can be conveyed to the pipe wall, where they react with corrosion products and/or with the wall biofilm. The mass transportation of a single substance is described by the advection-dispersion-reaction equation, which is written thus [5]:

$$
\frac{\partial C}{\partial t}=d_{l} \frac{\partial^{2} C}{\partial x^{2}}-v \frac{\partial C}{\partial x}-r
$$

where: $C=C(x, t)$ is the free residual chlorine concentration and which depends on the curvilinear abscissa $x \in[0 ; L]$ measured along the pipe and the time $t>0$ (greater than the initial moment $t=0$ ); $d_{1}$ is the longitudinal dispersion coefficient; $r=r(C)$ is the reaction rate inside the pipe, depending on concentration and $\mathrm{v}$ is average velocity.

The reaction rate on the pipe is the sum between the reaction rate inside the bulk flow in the pipe and the reaction rate at the pipe wall. This relation can be written thus [5]:

$$
r=k_{b} C^{n}+k_{g w} \frac{4}{D} C
$$

where: $\mathrm{n}$ is the reaction order $\left(\mathrm{n}=0\right.$, for a 0 order reaction; $\mathrm{n}=1$, for $1^{\text {st }}$ order reaction and $\mathrm{n}=2$, for a $2^{\text {nd }}$ order reaction); $\mathrm{k}_{\mathrm{b}}$ is the reaction constant in the bulk flow in the pipe and $\mathrm{kg}_{\mathrm{gw}}$ is the reaction coefficient at the pipe wall.

In order to perform the qualitative analysis of water in distribution networks, first, the hydraulic simulation must be performed. Following this simulation, results are obtained regarding flow rates, velocities, load losses, Darcy coefficient, pressures, piezometric load, etc.

A separate calculation is to be performed in order to compute the Reynolds number, the mass transfer coefficient on pipe $\mathrm{k}_{\mathrm{f}}$ and the reaction coefficient at the pipe wall $\mathrm{k}_{\mathrm{gw}}$, calculated according to diameters and flows for a time variable water consumption.

The reaction coefficient at the pipe wall depends on the decreasing constant at the pipe wall $\left(\mathrm{k}_{\mathrm{w}}=0.3 \mathrm{~m} /\right.$ day $)$ and on the mass transfer coefficient on pipe [5]:

$$
k_{g w}=\frac{k_{w} k_{f}}{k_{w}+k_{f}} .
$$

The mass transfer coefficient on the pipe can be expressed through this equation:

$$
k_{f}=0.0149 \frac{d}{D}\left(\frac{v}{d}\right)^{1 / 3} \operatorname{Re}^{0.88}
$$

where: $\mathrm{d}$ is the molecular diffusivity of reactive compound $\left(\mathrm{d}=1.21 \cdot 10^{-9} \mathrm{~m}^{2} / \mathrm{s}\right.$ for chlorine in water $)$; is the pipe diameter; Re is the Reynolds number and $v$ is the water kinematic viscosity. The water temperature was considered $20^{\circ} \mathrm{C}$, so that the kinematic viscosity is equal to $1.01 \cdot 10^{-6} \mathrm{~m}^{2} / \mathrm{s}$.

In order to simulate the chlorine conveying in the distribution network in the hilly area, certain settings were performed: the simulation was carried out for 72 hours (3 days) starting at midnight (Day 1, 12:00 AM to Day 3, 11:59 PM) with a chosen hydraulic time increment of 1 minute. The time increment chosen for modeling the chlorine conveying was 0.03 minutes. For the inlet node, the tank, the chlorine concentration was considered equal to $0.48 \mathrm{mg} / \mathrm{L}$ (the amount that continuously enters the network). In the pipeline editing menu, at „Wall Reaction Coefficient”, the obtained values for reaction coefficients at pipe walls were entered, and for the bulk flow decay constant $\mathrm{k}_{\mathrm{b}}$ the value of 0,85 day $^{-1}$ was chosen, proposed by [5].

The overall reaction rate constant is given by the equation [9]:

$$
K=-k_{b}-\frac{k_{w} k_{f}}{r_{h}\left(k_{w}+k_{f}\right)} \text {, }
$$


where: $r_{h}$ is hydraulic radius of the pipe.

Water age is modelled as a chemical substance by assuming the order of reaction $\mathrm{n}$ as zero and reaction rate constant $\mathrm{K}$ as one in the chlorine reaction rate. This means any new water parcel that enters the network from a reservoir or source node has an age equal to zero. If the water parcel moves through the pipe segment from the source node $i$ to one node $\mathrm{j}$ in a single water quality time step $t$, the water age at node $\mathrm{j}$ is equal to $\mathrm{t}[9]$.

\section{RESULTS AND DISCUSSION}

The output data, in the hypothesis of water quality simulation, can contain chlorine concentration values for both nodes and network pipes, values of the reaction rate on network pipes, but also the water age.

Figure 2 shows the variation of chlorine concentration $(\mathrm{mg} / \mathrm{L})$ for the distribution network studied in 2 periods of the day: at 4:00 a.m. when water consumption is reduced and at 8:00 a.m. when peak consumption is considered.

a)

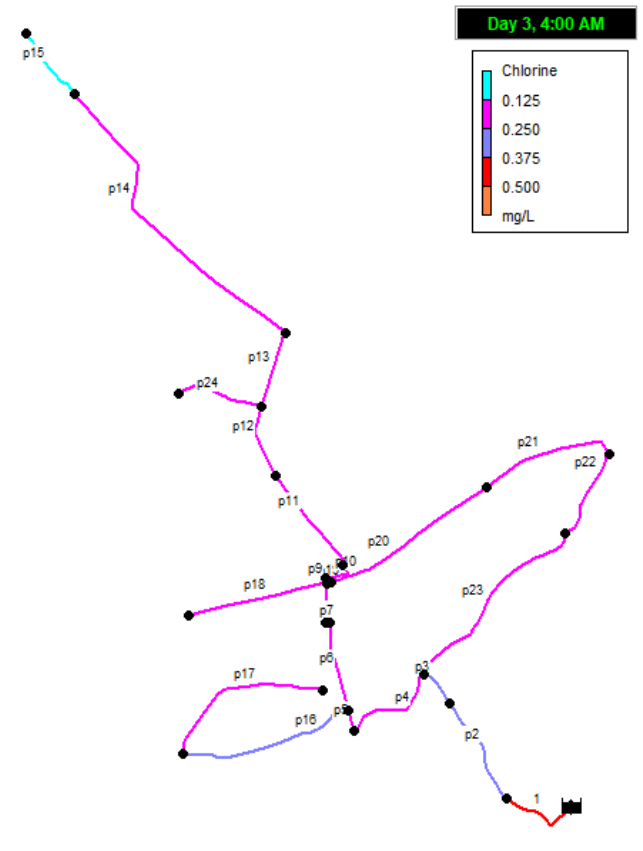

b)

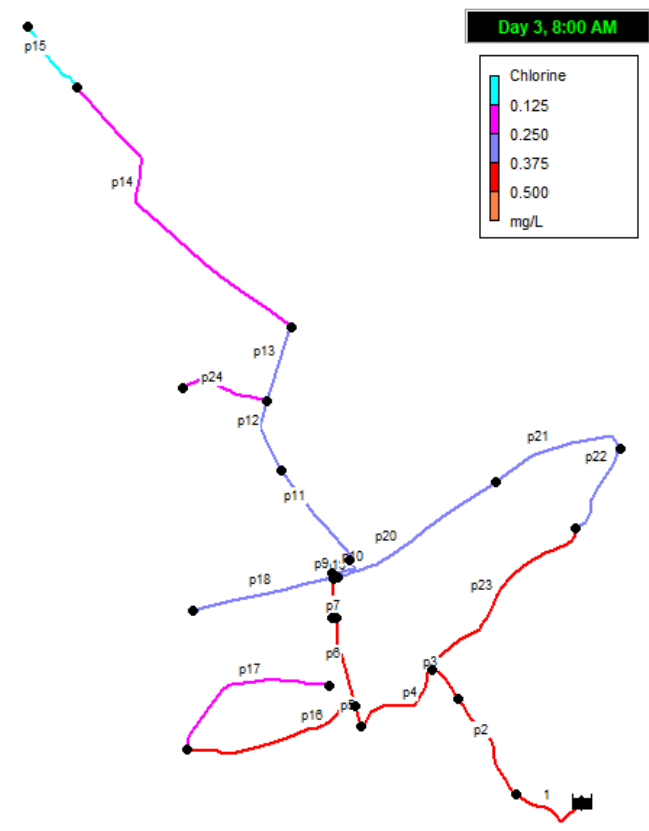

Fig. 2. Chlorine concentration variation in the network, for the $1^{\text {st }}$ degree decreasing: a) decreased consumption (Day 3, 4:00 AM) and b)increased consumption (Day 3, 8:00 AM)

It can be seen from Table 3 that, for the first order reaction in the fluid volume and at the pipe wall of the two analyzed situations, the consumers from section p15 are the most disadvantaged in terms of water quality, the chlorine concentration reaching values between 0.063 and $0.093 \mathrm{mg} / \mathrm{L}$. The favored consumers, in terms of water quality, are those from the first section $\mathrm{p} 1$ (that exits from the tank), with maximum values of chlorine concentration between 0.423 and $0.473 \mathrm{mg} / \mathrm{L}$.

In order to compare the values obtained in the case of the $1^{\text {st }}$ order reaction in the fluid volume and at pipe wall and the $2^{\text {nd }}$ order reaction in the fluid volume, this simulation was performed for the same chosen time intervals (Day 3, 4:00 a.m. and 8:00 a.m.). The values of chlorine concentrations are presented in Table 3 for each network pipe together with the reaction rate. It is specified that the $\mathrm{kgw}_{\mathrm{gw}}$ values in the table are entered in the module, but in EPANET they have been entered with a negative value. Also, the values of the obtained reaction rate are entered in absolute value.

Table 3. Chlorine concentrations $\mathrm{C}(\mathrm{mg} / \mathrm{L})$ and reaction rate on network pipes $(\mathrm{mg} / \mathrm{L} \cdot$ day), computed for $1^{\text {st }}$ and $2^{\text {nd }}$ order reactions 


\begin{tabular}{|c|c|c|c|c|c|c|c|c|c|}
\hline \multirow{3}{*}{$\begin{array}{c}\text { ID } \\
\text { EPANET }\end{array}$} & \multirow{3}{*}{$\begin{array}{c}\mathrm{kgw}_{\mathrm{gw}} \\
\text { (m/day) }\end{array}$} & \multicolumn{4}{|c|}{$1^{\text {st }}$ order reaction } & \multicolumn{4}{|c|}{$2^{\text {nd }}$ order reaction } \\
\hline & & \multicolumn{2}{|c|}{$\begin{array}{c}\text { Day 3, } \\
\mathrm{t}=4: 00 \text { AM }\end{array}$} & \multicolumn{2}{|c|}{$\begin{array}{c}\text { Day 3, } \\
\mathrm{t}=8: 00 \mathrm{AM}\end{array}$} & \multicolumn{2}{|c|}{$\begin{array}{c}\text { Day 3, } \\
\mathrm{t}=4: 00 \mathrm{AM}\end{array}$} & \multicolumn{2}{|c|}{$\begin{array}{c}\text { Day 3, } \\
\mathrm{t}=8: 00 \mathrm{AM}\end{array}$} \\
\hline & & $\mathrm{r}$ & $\mathrm{C}$ & $\mathrm{r}$ & $\mathrm{C}$ & $\mathrm{r}$ & $\mathrm{C}$ & $\mathrm{r}$ & $\mathrm{C}$ \\
\hline p1 & 0.2493 & 1.61 & 0.423 & 3.11 & 0.473 & 1.43 & 0.429 & 2.90 & 0.474 \\
\hline p2 & 0.2484 & 1.18 & 0.312 & 2.99 & 0.458 & 1.06 & 0.331 & 2.78 & 0.458 \\
\hline p3 & 0.2471 & 0.97 & 0.260 & 2.94 & 0.452 & 0.88 & 0.282 & 2.75 & 0.454 \\
\hline $\mathrm{p} 4$ & 0.2248 & 0.66 & 0.224 & 2.50 & 0.432 & 0.58 & 0.251 & 2.32 & 0.437 \\
\hline p5 & 0.2360 & 0.76 & 0.210 & 2.88 & 0.416 & 0.72 & 0.240 & 2.66 & 0.421 \\
\hline p6 & 0.2171 & 0.59 & 0.196 & 2.53 & 0.405 & 0.53 & 0.225 & 2.35 & 0.409 \\
\hline p7 & 0.2139 & 0.53 & 0.182 & 2.45 & 0.398 & 0.48 & 0.214 & 2.22 & 0.393 \\
\hline p8 & 0.2125 & 0.53 & 0.184 & 2.34 & 0.384 & 0.47 & 0.213 & 2.20 & 0.393 \\
\hline p9 & 0.2255 & 0.65 & 0.180 & 2.42 & 0.337 & 0.62 & 0.212 & 2.33 & 0.351 \\
\hline p10 & 0.2243 & 0.62 & 0.173 & 2.33 & 0.327 & 0.59 & 0.205 & 2.18 & 0.334 \\
\hline p11 & 0.2193 & 0.52 & 0.152 & 2.18 & 0.311 & 0.49 & 0.181 & 2.08 & 0.324 \\
\hline p12 & 0.2115 & 0.43 & 0.137 & 1.98 & 0.296 & 0.40 & 0.164 & 1.88 & 0.308 \\
\hline p13 & 0.1932 & 0.18 & 0.151 & 1.71 & 0.283 & 0.10 & 0.183 & 1.62 & 0.297 \\
\hline p14 & 0.1527 & 0.15 & 0.149 & 0.87 & 0.186 & 0.06 & 0.189 & 0.84 & 0.207 \\
\hline p15 & 0.0576 & 0.07 & 0.063 & 0.21 & 0.093 & 0.03 & 0.098 & 0.20 & 0.130 \\
\hline p16 & 0.1607 & 0.29 & 0.266 & 1.87 & 0.376 & 0.15 & 0.308 & 1.71 & 0.384 \\
\hline p17 & 0.1075 & 0.21 & 0.197 & 0.89 & 0.238 & 0.10 & 0.243 & 0.82 & 0.261 \\
\hline p18 & 0.0791 & 0.21 & 0.213 & 0.67 & 0.251 & 0.10 & 0.263 & 0.57 & 0.275 \\
\hline p19 & 0.1174 & 0.25 & 0.173 & 0.47 & 0.141 & 0.17 & 0.216 & 0.44 & 0.167 \\
\hline p20 & 0.1455 & 0.21 & 0.201 & 1.14 & 0.279 & 0.10 & 0.245 & 1.03 & 0.294 \\
\hline p21 & 0.1915 & 0.24 & 0.209 & 2.03 & 0.339 & 0.13 & 0.247 & 1.89 & 0.348 \\
\hline p22 & 0.1916 & 0.25 & 0.216 & 1.99 & 0.366 & 0.13 & 0.252 & 1.84 & 0.374 \\
\hline p 23 & 0.2061 & 0.60 & 0.210 & 2.42 & 0.411 & 0.53 & 0.239 & 2.24 & 0.416 \\
\hline p24 & 0.0714 & 0.19 & 0.181 & 0.59 & 0.221 & 0.09 & 0.226 & 0.50 & 0.244 \\
\hline
\end{tabular}

As can be seen in Table 3, the obtained values for reaction rate are lower in the case of the $2^{\text {nd }}$ order reaction, which means that there is a slower decrease of chlorine in the case of the $2^{\text {nd }}$ order reaction compared to the $1^{\text {st }}$ order reaction. In the case of chlorine concentration, it can be seen that the values obtained for the $2^{\text {nd }}$ order reaction are higher than those of the $1^{\text {st }}$ order reaction.

In general, it is considered that the results obtained for the $2^{\text {nd }}$ order reaction in the fluid volume are closer to reality than the results obtained for the $1^{\text {st }}$ order reaction in the fluid volume [10].

Water age in drinking water distribution systems is complicated as water of various ages is often mixed, especially in networks with interconnected pipe loops or multiple sources. It can be further influenced by diurnal flow patterns and seasonal demand, such that more water is used in dry seasons compared to wet seasons. Increased water age does not directly influence disinfectant residual stability, however, it is known to result in reduced disinfectant residuals and elevated DBP (disinfection by-product) formation due to a longer reaction time. Prolonged water age often happens in stagnation and long-distance distribution [2].

Figure 3 shows the water age in network pipes. Thus the age differences can be noticed due to distinct colors, forming, as a whole, a colored thematic map. The difference between the two maps can be noticed because in Fig. 3.a) the water age during night time is being represented when consumption is reduced and in Fig. 3.b) the water age in the first hours of the morning is being shown when water consumption has its highest values. Therefore, the shortest period of water stagnation is observed in pipes that are close to the tank, while the highest water age is noticed in the system's extremities (the most remote areas). 
a)

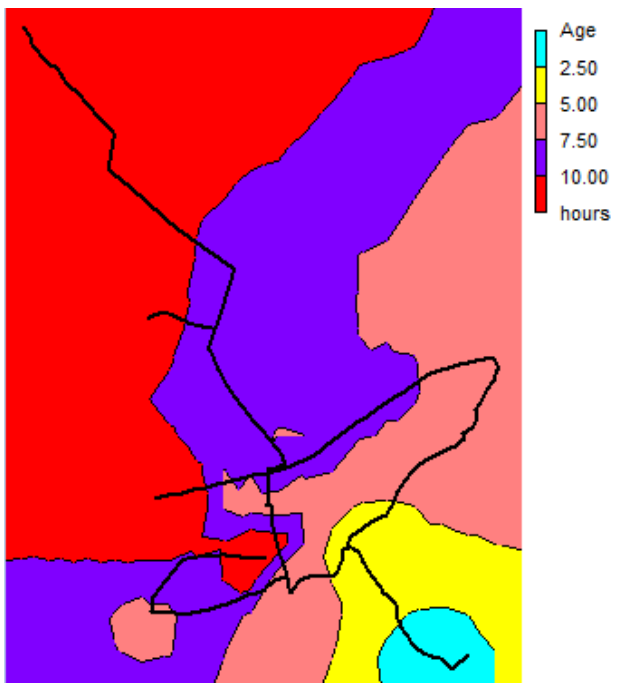

b)

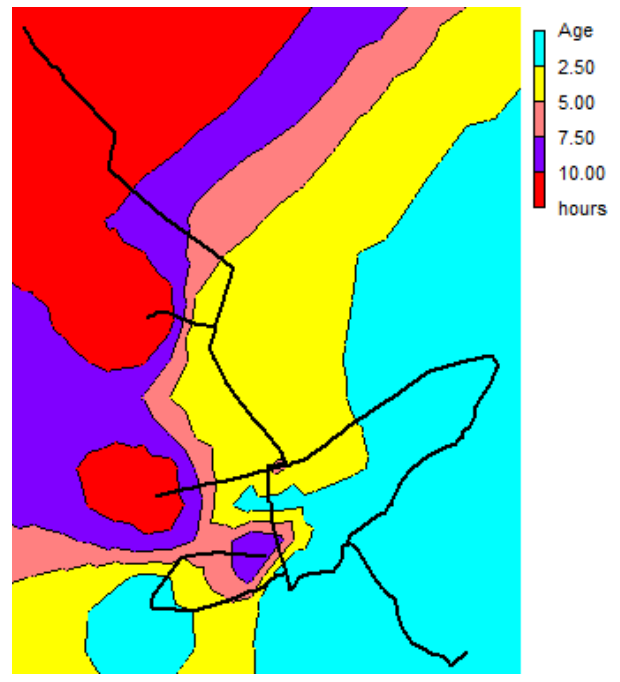

Fig. 3. Water age in network pipes - graphical representation via thematic maps; a)Age at 52:00 hours and b)Age at 56:00 hours

The significant water age, accompanied by a lack of the required concentration of disinfectant may result in the development of microorganisms, deposition of sediments, and deterioration of water quality [11].

\section{CONCLUSIONS}

According to regulations in force, the chlorine concentration must have a value higher than 0.1 $\mathrm{mg} / \mathrm{L}$ on the distribution network's route. Following the calculations performed for the $1^{\text {st }}$ order reaction, section p15 does not meet this condition. However, it can be seen that the maximum values of chlorine concentration are reached on the sections in the area close to the tank. Thus, from a quality point of view, the ending areas within the distribution network are disadvantaged compared to those that are closer to the source. This inconvenience is due to the fact that in those areas flow is very low, and the chlorine concentration depends on the flow variation.

In the case of water age in network pipes, it can be seen from the graph that the area on a red background is the most deficient area. In pipes from that area, the water flow velocity is below the limit of $0.7 \mathrm{~m} / \mathrm{s}$, but also flows record low values. These aspects contribute both to the sharp decrease of chlorine load and to the increasing of water age in certain pipes in the studied distribution network.

The research will be continued when the system is operational and its calibration can be performed.

\section{References}

1. Ahmad J.I., Liu G., van der Wielen P.W.J.J., Medema G., van der Hoek J.P., Effects of cold recovery technology on the microbial drinking water quality in unchlorinated distribution systems, Environmental Research 183 (2020) 109175, Elsevier.

2. Li R.A., McDonald J.A., Sathasivan A., Khan S.J., Disinfectant residual stability leading to disinfectant decay and by-product formation in drinking water distribution systems: A systematic review, Water Research 153 (2019) 335-348.

3. Agafiței A., Gabor V., Environmental Engineering - course, PIM Publishing house, Chapter 1, Iasi, pp. 14-46 (2018).

4. Țuțuianu A.E., Calculation program for monitoring the quality of water in water distribution networks, (in Romanian), PhD Thesis, Technical University of Civil Engineering Bucharest, Faculty of Hydrotechnics, Bucharest, Romania (2013). 
5. Georgescu S.C., Georgescu A.M., Epanet Manual (in romanian), Printech Publishing house, ISBN 978-606-23-0319-8, Bucharest, Romania (2014).

6. Georgescu A.M., Georgescu S.C., Chlorine concentration decay in the water distribution system of a town with 50000 inhabitants, UPB Scientific Bulletin D-74-1 (2012) 103-114.

7. Georgescu A.M., Georgescu S.C., Ciulacu C., Moiceanu A., Numerical modeling of chlorine transport through the water supply network of a locality with about 10000 inhabitants (in romanian), $4^{\text {th }}$ Conference of Hydroenergeticians from Romania Dorin Pavel, vol. I, May 2627, Bucharest (2006) 141-152.

8. Romanian Standard 1343-1, Water supplies. Calculation of drinking water supply quantities in urban and rural sites, Annex 2 (2006).

9. Nono D., Basupi I., Odirile P.T., Parida B.P., The effects of hydraulic performance and operation interventions on water quality: The case of Phakalane water distribution system in Botswana, Physics and Chemistry of the Earth 108 (2018) 48-59.

10. Georgescu A.M., Georgescu S.C., Numerical modelling of chlorine distribution in an urban water supply system, Environmental Engineering and Management Journal 12 (4) (2013) 657664.

11. Musz-Pomorska A., Widomski M.K., Matczuk A., Sadura K., Modeling chlorine distribution in water supply system utilizing empirically determined chlorine decay rate, $11^{\text {th }}$ Conference on Interdisciplinary Problems in Environmental Protection and Engineering EKO-DOK 2019, April 8-10, Poland, E3S Web of Conference 100 (2019) 422-429. 